\title{
Evaluation of Co-administration of Roselle Water Extract (Hibiscus sabdariffa L.) and Aspirin for Antiplatelet Therapy in Male Sprague-Dawley Rats
}

\author{
Zahriah $^{1,2}$, Fadlina Chany Saputri ${ }^{3, *}$
}

\section{Zahriah $^{1,2}$, Fadlina Chany \\ Saputri ${ }^{3, *}$ \\ 'Graduate Program, Faculty of Pharmacy, Universitas Indonesia, Kampus UI Depok, 16424, INDONESIA. \\ 2Pharmacy Program, Politeknik Kesehatan Kementerian Kesehatan Pangkalpinang, 33684, INDONESIA \\ ${ }^{3}$ Department of Pharmacology, Faculty of Pharmacy, Universitas Indonesia, Kampus UI Depok, 16424, INDONESIA. \\ Correspondence \\ Fadlina Chany Saputri}

Department of Pharmacology, Faculty of Pharmacy, Universitas Indonesia, Kampus UI Depok, 16424, INDONESIA.

Phone no: +62 217270031 ;

E-mail: fadlina.chany@farmasi.ui.ac.id History

- Submission Date: 15-12-2020;

- Review completed: 11-01-2021;

- Accepted Date: 13-01-2021.

DOI : 10.5530/pj.2021.13.70

Article Available online http://www.phcogj.com/v13/i2

\section{Copyright}

(C) 2021 Phcogj.Com. This is an openaccess article distributed under the terms of the Creative Commons Attribution 4.0 International license.

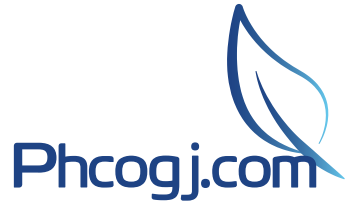

\begin{abstract}
Background: Various herbal side effects caused by interactions between herbs and drugs have been reported and reviewed. For instance, roselle water extract and aspirin have similar functions in maintaining cardiovascular function. Objective: This study aimed to investigate the effect of roselle water extract on aspirin pharmacodynamics observed through the parameters of bleeding time, survival rate and the number of microthrombus that induced thromboembolism in rats. Materials and Methods: Male Sprague-Dawley rats were divided into two different experimental group for bleeding time and survival rate assay. Roselle water extract was given in three various doses (12.5 mg, $25 \mathrm{mg}, 50 \mathrm{mg} / 200 \mathrm{~g} \mathrm{BW}$ ) for seven days followed by aspirin on the last treatment. Results: Results showed that the co-administration of roselle water extract and aspirin did not cause significant changes in the increase in bleeding time, the number of animals that survived and the number of microthrombus. Conclusion: Therefore, roselle water extract does not affect the pharmacodynamics of aspirin. Key words: Roselle water extract, Aspirin, Bleeding time, Survival rate, Thromboembolism.
\end{abstract}

\section{INTRODUCTION}

The use of numerous herbs has been extensively studied in terms of the important aspects of herbs. Various herbal side effects caused by herb-drug interaction have been reported and reviewed. The interactions between herbs and drugs have a higher potential than the interactions between conventional drugs because of the number of active components contained in herbs and because the conventional or synthetic drugs generally only contain a single chemical entity. ${ }^{1}$ Some cases of herbal-drug interactions include the ginkgodiuretic thiazide interaction, which causes an increase in blood pressure; the ginkgo-trazodone interaction, which causes coma; ginsengphenelzine interaction, which induces mania; and ginkgo-aspirin interactions, which causes hyphema. $^{2}$

Based on the data shown by Tsai et al. (2012), as many as 90 incidents caused by interactions between herbs and conventional drugs in the treatment of cardiovascular systems were identified. Aspirin is one of the drugs used for cardiovascular function maintenance and one of the drugs often used in conjunction with herbs. In a literature study, 36 incidents caused by the interactions between herbs and aspirin were identified. ${ }^{3}$

Low-dose aspirin has antiplatelet activity. Aspirin is a relatively selective inhibitor of the concentitutive isoforms of cyclooxygenase- 1 . The mechanism of action of aspirin in inhibiting platelet function is through the acetylation of the cyclooxygenase platelet enzyme that is in its essential amino acid serine 529. This reaction prevents access to the substrate (arachidonic acid) binding to the catalytic site of the enzyme in the amino acid tyrosine 385 , thereby resulting in an irreversible inhibition of thromboxane formation. ${ }^{4}$

Aspirin is the gold-standard antiplatelet agent. It has shown to be effective as a preventive therapy drug in patients who are at risk of cardiovascular disease (primary prevention). It is also used as a therapy drug in patients who have had one or more cardiovascular diseases (secondary prevention). ${ }^{5}$

According to Liperoti et al. (2017), the use of herbs tends to be more dominant than the use of conventional medicines in the management of cardiovascular disease. One herb that is believed to have efficacy in maintaining cardiovascular function is roselle water extract (Hibiscus sabdariffa L.). ${ }^{6}$ Roselle water extract has antioxidant ${ }^{7,8}$, antihypertensive, anticoagulant and antiplatelet activities. $^{10}$

Roselle water extract can inhibit platelet aggregation in vitro, as indicated by the inhibitory activity of collagen. In addition to thrombin that possesses an inhibitory activity, adenosine diphosphate (ADP) is produced by rosella water extract in relation to anticoagulants. The inhibition of collagen, ADP and thrombin influences haemostasis. ${ }^{10}$

Furthermore, roselle water extract has been used in the community for years and is utilised in various preparations, such as tea, flavoured drinks and also food colouring. Considering that roselle water extract has a variety of uses, researchers used it together with drugs, thereby having the potential to cause interaction. 
The presence of drug interactions can cause severity at varying levels, ranging from conditions that can still be tolerated to conditions that can cause death. ${ }^{2}$ Therefore, researchers intend to investigate the effect of rosella water extract on the pharmacodynamic effects of aspirin, so that the effects of possible interactions can be identified.

\section{MATERIALS AND METHODS}

\section{Materials and animals}

Roselle water extract (Hibiscus sabdariffa L.) was obtained from the Research Institute for Medicinal and Aromatic Plants (Bogor, Indonesia), with the test certificate number 369/T/LAB/V/18. Aspirin, $0.9 \%$ saline, epinephrine and collagen were acquired from the same company (Sigma Aldrich, China). Meanwhile, neutral buffer formalin (NBF) 10\% (Indogen, Jakarta, Indonesia) and carboxymethyl cellulose (Daiichi, Japan) were also utilised in this study.

\section{Phytochemical screening of roselle water extract}

The presence of metabolite in the plant extracts was identified by phytochemical screening. The screening was performed using standard procedures described by Sakti, et al. (2019). ${ }^{11}$ The Dragendorff method was used for alkaloid screening with quninine used as a positive control. Briefly, alkaloid test was performed by dissolving $100 \mathrm{mg}$ extract in $9 \mathrm{ml}$ of aquadest in test tube, then added $1 \mathrm{ml}$ of $10 \% \mathrm{HCl}$ solution. The mixture was heated at $70^{\circ} \mathrm{C}$ for $1 \mathrm{~min}$. After that, to the test tube was added $1 \mathrm{ml}$ of Dragendorff solution.

The shinoda test was used for flavonoids with cathecin as a positive control. Briefly, $100 \mathrm{mg}$ sample was dissolved in $10 \mathrm{ml}$ of $96 \%$ ethanol. Then, $5 \mathrm{ml}$ sample solution in the test tube was added 4 drops of concentrated $\mathrm{HCl}$ and $100 \mathrm{mg}$ of magnesium powder. Pink color showed the presence of flavonoid. Furthermore, $\mathrm{HCl} 2 \mathrm{~N}$ was used for saponin screening, $3 \% \mathrm{FeCl}_{3}$ for phenolic, $\mathrm{NaCl}$-gelatin for tannins, Lieberman Bourchard for terpenoids, and Molisch for glycosides.

The phytochemical screening showed the presence of alkaloids, flavonoids, saponins, phenolic, tannins, terpenoids, and glycosides in the extract.

\section{Total phenolic content (TPC) determination of roselle water extract}

Total Phenolic Content of roselle water extract was determined using Folin-Ciocalteu reagent following standard procedure of Sakti, et al. (2019). ${ }^{11}$ Briefly, a volume of $25 \mu \mathrm{l}$ extract solution was mixed with 100 $\mu \mathrm{l}$ Folin-Ciocalteu reagent (diluted $1: 4(\mathrm{v} / \mathrm{v})$ with ddH2O) and shaken on 96-well microplate, then left to stand for $4 \mathrm{~min}$ at room temperature. Into the well added $75 \mu \mathrm{Na} 2 \mathrm{CO} 3$ solution $(\mathrm{w} / \mathrm{v})$, then the mixture shaken for $60 \mathrm{~s}$. Subsequently the reaction mixture was incubated for $2 \mathrm{~h}$ at room temperature. The absorbance was read at $756 \mathrm{~nm}$ using a microplate reader (VersaMax Microplate Reader, USA). Total phenolic content of roselle water extract was found at $1.396 \%$.

\section{High performance liquid chromatography (HPLC)} analysis of roselle water extract

Roselle water extract was analysed by HPLC using the Agilent 1200 series system, that is, the HPLC-0053 system (Agilent Technologies, Santa Clara, CA), equipped with diode-array detectors (Agilent, Serial No.: DE 60555816) and C18 columns (Inertsil ODS-3, 5.0 $\mu \mathrm{m}$ ). The extract contains chlorogenic acid and gallic acid, which has an antiplatelet activity. ${ }^{12-13}$ Chlorogenic acid and gallic acid chromatograms will be published elsewhere. Moreover, the extract was analysed using a validated HPLC method described in our previous studies. ${ }^{14}$

\section{Animal experimental design}

Male Sprague-Dawley rats with a body weight (BW) of 100-200 grams were purchased from the Bogor Agricultural Institute. The use of animals in this study was ethically approved by the ethics committee of a medical faculty in Universitas Indonesia, with the approval number 0646/UN2.F1/ETIK/2018. Before experiment, the acclimatization was carried out for two weeks. All animal had a normal diet and free access to a drinking water. The animals were placed in a well-ventilated cage with 12 hours light-dark periods and with a constant physical ambient temperature $\left(25 \pm 5^{\circ} \mathrm{C}\right)$. The animals were observed for the activity and weighed every day. Only healthy animals were included in this study.

A total of 36 rats were divided into six groups with six rats individually for tail bleeding assay. Each group was treated differently as follows: normal control $(0.5 \% \mathrm{CMC}$, orally for $7 \mathrm{~d})$ was labeled as vehicle, aspirin $(2 \mathrm{mg} / 200 \mathrm{~g} \mathrm{BW}$, orally for $7 \mathrm{~d}$ ), roselle (roselle water extract at $50 \mathrm{mg} / 200 \mathrm{~g} \mathrm{BW}$, orally for $7 \mathrm{~d}$ ), RD1A (roselle water extract at 12.5 $\mathrm{mg} / 200 \mathrm{~g} \mathrm{BW}$ orally for $7 \mathrm{~d}+$ aspirin at $2 \mathrm{mg} / 200 \mathrm{~g} \mathrm{BW}$ orally on $7^{\text {th }}$ day), RD2A (roselle water extract at $25 \mathrm{mg} / 200 \mathrm{~g}$ BW orally for $7 \mathrm{~d}+$ aspirin at $2 \mathrm{mg} / 200 \mathrm{~g} \mathrm{BW}$ orally on $7^{\text {th }}$ day) and RD3A (roselle water extract at $50 \mathrm{mg} / 200 \mathrm{~g} \mathrm{BW}$ orally for $7 \mathrm{~d}+$ aspirin at $2 \mathrm{mg} / 200 \mathrm{~g} \mathrm{BW}$ orally on $7^{\text {th }}$ day).

Another total of 42 rats were divided into seven groups with six rats individually for survival rate assay by pulmonary thromboembolism model. Each group was treated differently as follows: normal control ( $0.5 \%$ CMC orally for $7 \mathrm{~d}$; normal saline injection), vehicle (0.5\% CMC orally for $7 \mathrm{~d}$; collagen/epinephrine injection), aspirin $(2 \mathrm{mg} / 200 \mathrm{~g}$ BW orally for $7 \mathrm{~d}$; collagen/epinephrine injection), roselle (roselle water extract at $50 \mathrm{mg} / 200 \mathrm{~g} \mathrm{BW}$ orally for $7 \mathrm{~d}$; collagen/epinephrine injection), RD1A (roselle water extract at $12.5 \mathrm{mg} / 200 \mathrm{~g}$ BW orally for $7 \mathrm{~d}+$ aspirin at $2 \mathrm{mg} / 200 \mathrm{~g}$ BW orally on $7^{\text {th }}$ day; collagen/epinephrine injection), RD2A (roselle water extract at $25 \mathrm{mg} / 200 \mathrm{~g} \mathrm{BW}$ orally for 7 $\mathrm{d}+$ aspirin at $2 \mathrm{mg} / 200 \mathrm{~g}$ BW orally on $7^{\text {th }}$ day; collagen/epinephrine injection) and RD3A (roselle water extract at $50 \mathrm{mg} / 200 \mathrm{~g} \mathrm{BW}$ orally for $7 \mathrm{~d}+$ aspirin at $2 \mathrm{mg} / 200 \mathrm{~g}$ BW orally on $7^{\text {th }}$ day; collagen/epinephrine injection).

\section{Pharmacodynamic interactions evaluation of roselle water extract and aspirin}

The interaction evaluation was conducted through bleeding time assay and survival rate assay by pulmonary thromboembolism model as described by Saputri et al (2017). ${ }^{15}$ Such treatment was administered orally for 7 days. In the co-administration groups (RD1A, RD2A and RD3A), aspirin was administered 30 minutes after the administration of roselle water extract on day 7. Each dose of roselle water extract was suspended in $0.5 \% \mathrm{CMC}$ to obtain the suspension of extract. While aspirin was dissolved in water.

\section{Tail bleeding time assay}

Bleeding time of rats was tested by injuring their tails. Prior to tail injury, each rat was anaesthetised using xylazine $(10 \mathrm{mg} / \mathrm{kg} \mathrm{BW})$ and ketamine $(100 \mathrm{mg} / \mathrm{kg} \mathrm{BW})$. The rat's tail was injured by incising the tip of the rat tail for $2 \mathrm{~cm}$ using surgical scissors. The tail was placed in a falcon tube containing $0.9 \%$ saline. The blood coming out of the rat's tail was seen in the falcon tube with a certain time interval. From the time the blood began to flow until the time the blood stopped flowing is regarded as the bleeding time. ${ }^{16}$

\section{Survival rate assay by pulmonary thromboembolism model}

The survival rate test was performed on rats by injecting an intravenous induction solution through the rat's tail. ${ }^{17}$ The induction solution used 
was collagen at $0.21 \mathrm{mg} / 200 \mathrm{~g} \mathrm{BW}$ and epinephrine at $0.07 \mathrm{mg} / 200 \mathrm{~g}$ BW in $0.9 \%$ saline solution to induce pulmonary thromboembolism. While the normal group was given an injection of normal saline. Intravenous injection was given 1 hour after the administration of last treatment in each rat. The lethal and paralysis effects are observed for 15 minutes after induction. Calculations were performed on rats that died as well as those that survived due to the occurrence of thromboembolism induced by collagen and epinephrine. Rats survived if they could resume to normal activities after 1 hour of collagen and epinephrine administration. The survival rate (\%) was calculated based on the formula which described by Sakti et al. (2020). ${ }^{18}$

\section{Histopathology of a rat's lung}

The extracted part of a rat's lung was perfused with phosphate-buffered saline and $10 \% \mathrm{NBF}$. The parts of the lung were removed and stored in a container with $10 \% \mathrm{NBF}$. In the histology process, the isolated part of the lung was washed gradually with alcohol and xylen. Next, paraffinisation was performed. The part of the lung that was initialised was sliced into $5 \mu \mathrm{m}$ using a rotary microtone, stained with haematoxylin and eosin, cleaned again with xylen and then examined using a fluorescence microscope. ${ }^{19}$

\section{Statistical analysis}

The bleeding time assay data are presented as mean \pm SD (Standard Deviation). The Levene test was used to determine the homogeneity, while the Shapiro-Wilk test was used to analyzed the normality of data. The differences in mean was analyzed with ANOVA followed by Tukey and LSD post hoc analysis using SPSS v.22. Values of $p<0.05$ were considered to be statistically significant.

\section{RESULTS}

Effects of roselle water extract, aspirin, and coadministration on bleeding time assay

After a week administration, bleeding time was significantly increase in all the drug treatment groups (aspirin, roselle water extract, RD1A,
$\mathrm{RD} 2 \mathrm{~A}$, and $\mathrm{RD} 3 \mathrm{~A}$ ) compared to normal control group ( $<0.05$, Figure 1). Co-administration group showed slightly increase in bleeding time in dose dependent manner, with the highest mean value of bleeding time was shown by RD3A group. RD1A, RD2A, and RD3A groups did not induce a further prolongation in bleeding time compared to roselle water extract alone. Furthermore, the bleeding time in the coadministration groups did not significantly increase compared with that in the single aspirin group ( $\mathrm{p}>0.05)$.

Effects of roselle water extract, aspirin, and coadministration on survival rate in pulmonary thromboembolism model

Seven days of treatment with aspirin and roselle water extract increased the survival rate with the highest percentage of survival rate was demonstrated by aspirin (66.7\%). As shown in Table 1, co-administration groups increased the survival rate due to thromboembolism induction as well as the dose of roselle water extract increase.

Microthrombus formation in the lung was used to evaluate the reason of the animal death. In the aspirin, roselle and three co-administration groups (RD1A, RD2A, and RD3A), a number of microthrombus were formed and showed a significant decrease than that in the vehicle group. The microscopic images of microthrombus formed are shown in Figure 2.

However, in the co-administration groups (RD1A, RD2A and RD3A), the number of microthrombus formed did not decrease significantly compared with that in the single aspirin group. The analysis results of the number of microthrombus observed from the five fields of view are presented in Table 2.

\section{DISCUSSION}

Aspirin, when enters the body, it is rapidly hydrolysed into salicylic acid by the esterase enzyme found in the intestine. In this metabolic process, species differences have a significant effect related to the activity and specificity of the esterase enzyme as an aspirin-metabolising enzyme.

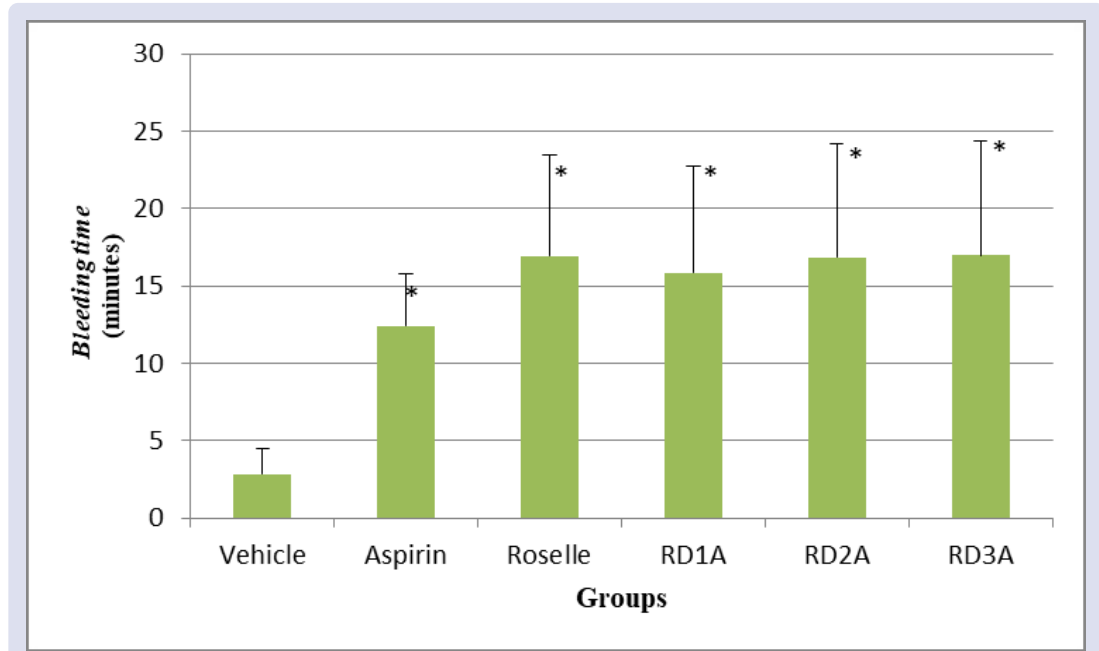

Figure 1: Graph of bleeding time. Note: $\left.{ }^{*}\right)$ Significantly different from the vehicle group, $p<0.05$. Data shows the mean with standard deviation (SD). Six groups consisting of the following: vehicle (0.5\% CMC; p.o.); aspirin ( $2 \mathrm{mg} / 200 \mathrm{~g} \mathrm{BW}$; p.o.); roselle (roselle water extract $50 \mathrm{mg} / 200 \mathrm{~g}$ BW; p.o.); RD1A: co-administration of dose 1 (roselle water extract $12.5 \mathrm{mg} / 200$ $\mathrm{g}$ BW + aspirin $2 \mathrm{mg} / 200 \mathrm{~g} \mathrm{BW}$; p.o.); RD2A: co-administration of dose 2 (roselle water extract $25 \mathrm{mg} / 200 \mathrm{~g} \mathrm{BW}+$ aspirin $2 \mathrm{mg} / 200 \mathrm{~g}$ BW; p.o.); RD3A: co-administration of dose 3 (roselle water extract $50 \mathrm{mg} / 200 \mathrm{~g} \mathrm{BW}+$ aspirin $2 \mathrm{mg} / 200 \mathrm{~g} \mathrm{BW}$; p.o.). 


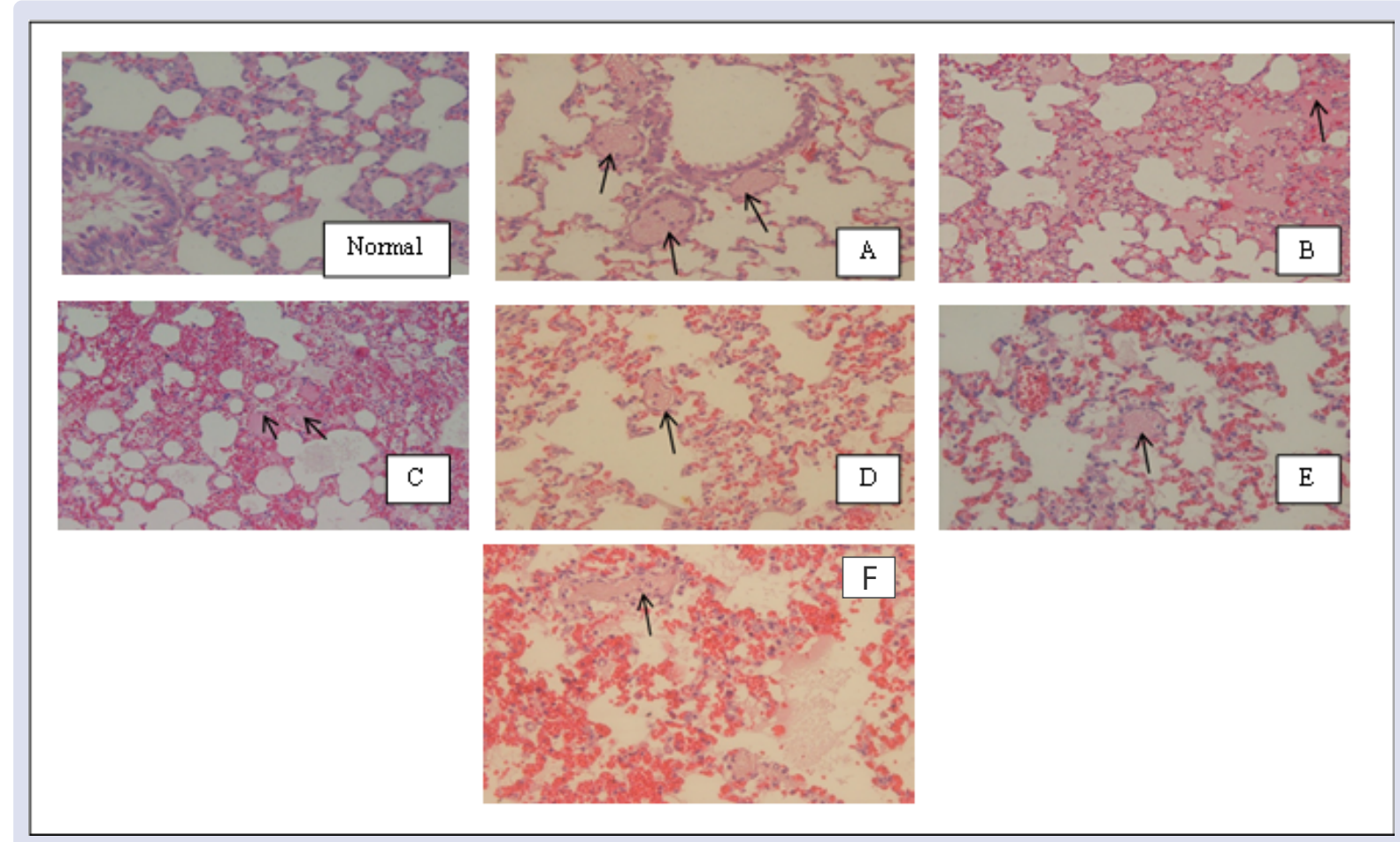

Figure 2: Microscopic images of microthrombus. Note: (A) vehicle: negative control (0.5\% CMC; p.o.); (B) aspirin (2 mg/200 g BW; p.o.); (C) roselle (roselle water extract $50 \mathrm{mg} / 200 \mathrm{~g} \mathrm{BW}$; p.o.); (D) RD1A: co-administration of dose 1 (roselle water extract $12.5 \mathrm{mg} / 200 \mathrm{~g} \mathrm{BW}+$ aspirin $2 \mathrm{mg} / 200 \mathrm{~g}$ BW; p.o.); (E) RD2A: co-administration of dose 2 (roselle water extract $25 \mathrm{mg} / 200 \mathrm{~g} \mathrm{BW}+$ aspirin $2 \mathrm{mg} / 200 \mathrm{~g}$ BW; p.o.); (F) RD3A: co-administration of dose 3 (roselle water extract $50 \mathrm{mg} / 200 \mathrm{~g} \mathrm{BW}+$ aspirin $2 \mathrm{mg} / 200 \mathrm{~g} \mathrm{BW}$; p.o.).

Table 1: Survival rate in rats with induced pulmonary thromboembolism.

\begin{tabular}{|c|c|c|c|c|c|}
\hline \multirow{3}{*}{ Group } & \multirow{3}{*}{$\mathrm{N}$} & \multicolumn{4}{|c|}{ Survival Rate } \\
\hline & & \multicolumn{2}{|c|}{ Died } & \multicolumn{2}{|c|}{ Survived } \\
\hline & & $\mathrm{n}$ & $\%$ & $\mathrm{~N}$ & $\%$ \\
\hline Normal & 6 & 0 & 0 & 6 & 100 \\
\hline Vehicle & 6 & 6 & 100 & 0 & 0 \\
\hline Aspirin & 6 & 2 & 33.3 & 4 & 66.7 \\
\hline Roselle & 6 & 3 & 50 & 3 & 50 \\
\hline RD1A & 6 & 4 & 66.7 & 2 & 33.3 \\
\hline RD2A & 6 & 4 & 66.7 & 2 & 33.3 \\
\hline RD3A & 6 & 3 & 50 & 3 & 50 \\
\hline
\end{tabular}

Note: Normal (0.5\% CMC; p.o.); vehicle: negative control (0.5\% CMC; p.o.); aspirin (2 mg/200 g BW; p.o.); roselle (roselle water extract $50 \mathrm{mg} / 200 \mathrm{~g} \mathrm{BW}$; p.o.); RD1A: co-administration of dose 1 (roselle water extract $12.5 \mathrm{mg} / 200 \mathrm{~g} \mathrm{BW}+$ aspirin $2 \mathrm{mg} / 200 \mathrm{~g}$ BW; p.o.); RD2A: co-administration of dose 2 (roselle water extract $25 \mathrm{mg} / 200 \mathrm{~g} \mathrm{BW}+$ aspirin $2 \mathrm{mg} / 200 \mathrm{~g}$ BW; p.o.); RD3A: co-administration of dose 3 (roselle water extract $50 \mathrm{mg} / 200 \mathrm{~g}$ BW + aspirin $2 \mathrm{mg} / 200 \mathrm{~g}$ BW; p.o.).

Table 2: Number of microthrombus observed from rats' lungs.

\begin{tabular}{lc}
\hline Group & Mean microthrombus \pm SD \\
\hline Vehicle & $5.7 \pm 0,9$ \\
Aspirin & $1.5 \pm 1,5^{*}$ \\
Rosella & $2.0 \pm 2,0^{*}$ \\
RD1A & $3.0 \pm 1,6^{*}$ \\
RD2A & $2.3 \pm 1,9^{*}$ \\
RD3A & $1.5 \pm 1,3^{*}$ \\
\hline
\end{tabular}

Note: vehicle: negative control (0.5\% CMC; p.o.); aspirin ( $2 \mathrm{mg} / 200 \mathrm{~g}$ BW; p.o.); roselle (roselle water extract 50 $\mathrm{mg} / 200 \mathrm{~g} \mathrm{BW}$; p.o.); RD1A: co-administration of dose 1 (roselle water extract $12.5 \mathrm{mg} / 200 \mathrm{~g} \mathrm{BW}+$ aspirin $2 \mathrm{mg} / 200$ g BW; p.o.); RD2A: co-administration of dose 2 (roselle water extract $25 \mathrm{mg} / 200 \mathrm{~g} \mathrm{BW}+$ aspirin $2 \mathrm{mg} / 200 \mathrm{~g} \mathrm{BW}$; p.o.); RD3A: co-administration of dose 3 (roselle water extract $50 \mathrm{mg} / 200 \mathrm{~g} \mathrm{BW}+$ aspirin $2 \mathrm{mg} / 200 \mathrm{~g}$ BW; p.o.). 
The esterase found in rats shows different specificities compared with the esterase found in humans. ${ }^{19}$ It is important to evaluate the coadministration consequency on platelet function.

Through testing the bleeding time, we can investigate the ability of a compound to affect the process of haemostasis in general and platelet activators in particular. Moreover, haemostasis plays a role in ceasing blood flow through cellular and biochemical mechanisms with the aim of preventing massive blood loss due to injury through blood clotting mechanism. The formation of a blood clot is certainly inseparable from the various factors involved in it. Among these factors are thromboxane A2, ADP, collagen and thrombin. ${ }^{21,22}$

Based on the study results, aspirin as a compound has indeed shown to be an antiplatelet drug, exhibiting its ability to influence haemostasis, especially in the process of inhibiting platelet activation and aggregation. This phenomenon can be observed from the significantly longer bleeding time in the group of rats that received aspirin than that in the vehicle group. The ability to increase bleeding time was also seen in a single roselle water extract group and three co-administration groups (RD1A, RD2A and RD3A). This activity is due to the inhibition of platelet activation by chlorogenic acid via $\mathrm{A} 2 \mathrm{~A}$ receptor/adenylate cyclase/cAMP/PKA activation, and consequently, the GPIIb/IIIa receptor activation and platelet secretion suppressed. ${ }^{23}$

As mentioned, in the group survival test, thromboembolism was induced by an intravenous injection of collagen-epinephrine solution. However, no significant differences were found between the groups in providing protection against thromboembolism events. The possible reason for such insignificance is that the initiation of platelet activation and the occurrence of platelet aggregation through exposure to external collagen are stronger than the ability of single roselle water extract or co-administration with aspirin in inhibiting thromboxane A2, ADP and collagen adhesion to platelets. In the end, aspirin and roselle water extract failed to significantly prevent thrombus formation; the formed thrombus then circulated and clogged the arteries in the lungs, thereby causing death.

The histopathological results of rat lungs in the survival rate test group showed that thromboembolism induction using the collagenepinephrine solution was successful. The successful thromboembolism was characterised by microscopic identification of microthrombus in the lungs of rats. In the aspirin, roselle and three co-administration groups (RD1A, RD2A and $\mathrm{RD} 3 \mathrm{~A}$ ), a number of microthrombus were formed and showed a significant decrease than that in the vehicle group. Thus, these compounds have a tendency to prevent thrombus formation induced by collagen-epinephrine solution.

On the basis of the microscopic image above, the intravascular exposure to collagen-epinephrine solution can cause microthrombus formation in the lungs of rats. The microthrombus formation can be seen in the pictures (A, B, C, D, E and F). Microthrombus was formed because of the presence of collagen and epinephrine, which initiate the activation of platelets. Activated platelets circulated in blood vessels and caused blockages in the pulmonary arteries of the lungs, ultimately causing occlusion of blood vessels. In addition to the formation of microthrombus, another condition that also caused the death of rats in this study is the occurrence of oedema in their lungs. One of the causes of pulmonary oedema is the formation of pulmonary embolism. The development of oedema secondary to pulmonary embolism is possible due to excessive perfusion. Extensive damage to blood vessels in the lungs due to embolism can cause excessive perfusion of the capillaries and generate 'dependent flow' or hydrostatic pulmonary oedema in this area. With increased flow and intracapillary pressure, the fluid will undergo extravasation. However, the rate of fluid loss is likely to increase with pathological increase in capillary permeability caused by pressure failure. Increased total lung volume causes an increase in pressure failure in the pulmonary capillaries. ${ }^{24}$

\section{CONCLUSION}

Rosella water extract co-administered with aspirin in three dose variations did not show significant changes in the increase in bleeding time, in the survival rate of rats with induced pulmonary thromboembolism and in the number of microthrombus formed. Therefore, roselle water extract does not affect the pharmacodynamics of aspirin.

\section{ACKNOWLEDGEMENT}

This work is supported by Faculty of Pharmacy, Universitas Indonesia and funded by Directorate of Research and Development, Universitas Indonesia.

\section{CONFLICTS OF INTEREST}

The authors declare there is no conflicts of interest in this study.

\section{CONTRIBUTION OF AUTHORS}

We declare that this work was done by the authors named in this article and all liabilities pertaining to claims relating to the content of this article will be borne by the authors.

\section{REFERENCES}

1. Izzo AA. Interactions between herbs and conventional drugs: Overview of the clinical data. Med Princ Pract. 2012;21(5):404-28.

2. Chen XW, Serag ES, Sneed KB, Liang J, Chew H, Pan SY, Zhou SF. Clinical herbal interactions with conventional drugs: from molecules to maladies. Curr Med Chem. 2011;18(31):4836-50.

3. Tsai HH, Lin HW, Simon Pickard A, Tsai HY, Mahady GB. Evaluation of documented drug interactions and contraindications associated with herbs and dietary supplements: A systematic literature review. Int J Clin Pract. 2012;66(11):1056-78

4. Schrör K. Aspirin and platelets: The antiplatelet action of aspirin and its role in thrombosis treatment and prophylaxis. Semin Thromb Hemost. 1997;23(4):349-56.

5. Baigent C, Blackwell L, Collins R, Emberson J, Godwin J. Aspirin in the primary and secondary prevention of vascular disease: a collaborative meta-analysis of individual participant data from randomised trials. Lancet. 2009;373(9678):1849-60.

6. Liperoti R, Vetrano DL, Bernabei R, Onder G. Herbal medications in cardiovascular medicine. J Am Coll Cardiol. 2017;69(9):1188-99.

7. Usoh IF, Akpan EJ, Etim EO, Farombi EO. Antioxidant actions of dried flower extracts of Hibiscus sabdariffa L. on sodium arsenite-Induced oxidative stress in rats. Pakistan J Nutr. 2005;4(3):135-41.

8. Mossalam HH, Abd-El Aty OA, Morgan EN, Youssaf SMS, Mackawy $\mathrm{AMH}$. Biochemical and ultra structure studies of the antioxidant effect of aqueous extract of Hibiscus sabdariffa on the nephrotoxicity induced by organophosphorous pesticide (Malathion) on the adult albino rats. J Am Sci. 2011;8(5):561-74.

9. Ojeda D, Jimenez-Ferrer E, Zamilpa A, Herrera-Arellano A, Tortoriello $J$, Alvarez L. Inhibition of angiotensin converting enzyme (ACE) activity by the anthocyanins delphinidin- and cyanidin-3-O-sambubiosides from Hibiscus sabdariffa. J Ethnopharmacol. 2010;127(1):7-10.

10. Rao TP, Htay HH, Yasuda NK, Sugino H, Ohkubo TH, Okamoto T, Suzuki K. Antioxidant and Anti-Thrombotic Properties of Selected Plant Extracts of Asia. Austin J Nutr Metab. 2014;1(1):6.

11. Sakti AS, Saputri FC, Muním A. Microscopic characters, phytochemical screening focus on alkaloid and total phenolic content of Uncaria gambir Roxb. and Uncaria sclerophylla Roxb. leaves. Pharmacogn J. 2019;11(1):119-23.

12. Lim M., Park YH, Son DJ, Kim MK, Lee Hoi-Seon. Antiplatelet activity of gallic acid and methyl gallate. Food Sci Biotechnol. 2004;13:806-9.

13. Chang SS, Lee VS, Tseng YL, Chang KC, Chen KB, Chen YL, Li CY. Gallic acid attenuates platelet activation and platelet-leukocyte aggregation: involving pathways of Akt and GSK3 $\beta$. Evid Based Complement Alternat Med. 2012;2012:8. 
14. Nurfaradilla SA, Saputri FC, Harahap Y. Effects of Hibiscus Sabdariffa Calyces aqueous extract on the antihypertensive potency of Captopril in the two-kidney-one-clip rat hypertension model. Evid Based Complement Alternat Med. 2019;2019.

15. Saputri F, Nabila N, Mun'im A. Combination of Ginger and Sappan Wood Extract Effect on In vivo Antithrombotic Activity Test. J Young Pharm. 2017;9(1):s46-8.

16. Zhou L, Wang S, Zhang Z, San Lau B, Pui Fung K, Chung Leung $P$, Zuo Z. Pharmacokinetic and pharmacodynamic interaction of Danshen-Gegen extract with warfarin and aspirin. J Ethnopharmacol. 2012;143(2):648-55

17. Azmi NU, Nityasa AR, Saputri FC. Antithrombotic effect of Mucuna pruriens L. and Coriandrum sativum. Pharmacogn J. 2019;11(2):413-7.

18. Sakti AS, Nityasa AR, Saputri FC. Effect of Uncaria gambir and Uncaria sclerophylla on pulmonary-thromboembolism mice. Pharmacogn $\mathrm{J}$. 2020;12(1):192-6.
19. Abhishek S, Deepak S, Singh VJ. Estimation efficacy of antithrombotic activity of various antiplatelet drugs in murine model. Innovare $\mathrm{J}$ Health Sci. 2013;1(1):16-8.

20. Bahar FG, Ohura K, Ogihara T, Imai T. Species difference of esterase expression and hydrolase activity in plasma. J Pharm Sci. 2012;101(10):3979-88.

21. Ogedegbe HO. An overview of hemostasis. Laboratory Medicine. 2002;33(12):948-53.

22. Hall JE. Guyton and Hall Textbook of Medical Physiology. (3rd ed). Philadelphia: Elsevier; 2016.

23. Fuentes E, Caballero J, Alarcon M, Rojas A, Palomo I. Chlorogenic acid inhibits human platelet activation and thrombus formation. PloS One. 2014;9(3):1-13.

24. Montgomery HE, Marshall M, Woolf I, Speechly-Dick ME. Pulmonary embolism as a cause of pulmonary edema. Clin Intens Care. 1995;6(4):184-8.

\section{GRAPHICAL ABSTRACT}

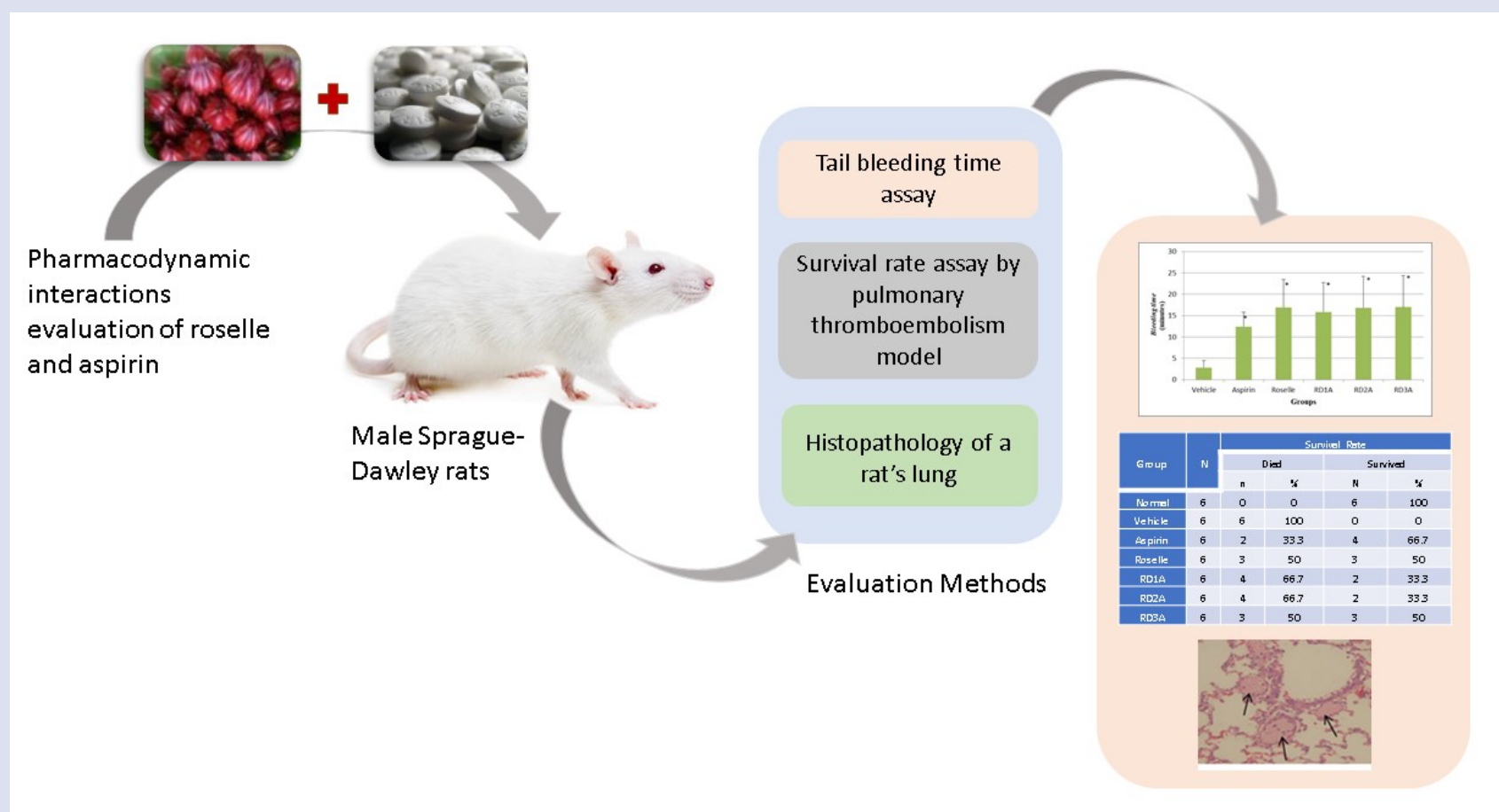

\section{ABOUT AUTHORS}

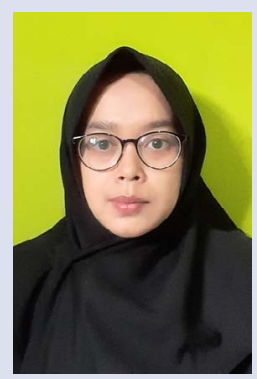

\section{Zahriah}

Master Student at Pharmaceutical Science-Pharmacology, Faculty of Pharmacy, Universitas Indonesia. Her focus research on herb - drug interaction: pharmacokinetics and pharmacodynamic aspect. 


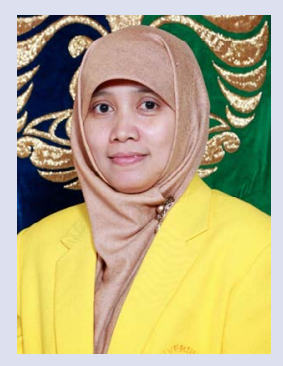

Dr. Fadlina Chany Saputri., M.Si., Apt.

Associate Professor at Department of Pharmacology, Faculty of Pharmacy, Universitas Indonesia. She has experience in the area of pharmacology and herbal medicine, working in drug discovery for metabolic disorder and degenerative diseases (such as diabetes mellitus, hypertension, hyperlipidemia, atheroschlerosis, etc)

Cite this article: Zahriah, Saputri FC. Evaluation of Co-administration of Roselle Water Extract (Hibiscus sabdariffa L.) and Aspirin for Antiplatelet Therapy in Male Sprague-Dawley Rats. Pharmacog J. 2021;13(2): 563-9. 